\title{
The virtual learning future
}

\author{
Vivienne Westbrook* \\ National Taiwan University, Taiwan
}

Since there is a real possibility that online courses will become the dominant informational platforms of the future universities need to address a range of issues from design and quality through to ethics and economics to ensure that the all-round investment required reaps positive outcomes. This paper addresses some of the issues that have confronted teachers and students engaged in online teaching and learning in eastern and western contexts. This paper concludes that Asian students are not necessarily poor online learners, as has often been suggested, but that they are alert to the importance, and real advantages, of personal interaction in the learning process. For this reason it is suggested that integrated hybrid virtual and classroom courses might prove more effective and elicit more positive responses from such students than courses that are conducted entirely online.

\section{Introduction}

As organizations across the world attempt to maintain a competitive edge in global business and education markets, the demand for online courses is steadily increasing. Theresa Chen has noted 'as continuous learning comes to be seen more and more as a necessity for almost everyone in our rapidly changing and increasingly global society, the demand for more flexible educational environments increases accordingly' (Chen, 2003, p. 37).

Since there is a real possibility that online courses will become the dominant informational platforms of the future we need to think more carefully about a range of issues from design and quality through to ethics and economics. In Towards a unified e-learning strategy (DfEE, July 2003), the British Government's Strategy Committee described e-learning as the miracle answer to Britain's educational and concomitant social problems. E-learning, they argue:

... is important because it can contribute to all the Government's objectives for education - to raising standards; improving quality; removing barriers to learning and participation in learning; preparing for employment; upskilling in the workplace and ultimately, ensuring that every learner achieves their full potential. (DfEE, 2003)

In spite of the Government's optimism, e-learning is far from being either a quick-fix solution or, indeed, a cheap alternative to traditional classroom teaching and learning.

\footnotetext{
${ }^{\star}$ Department of Foreign Languages and Literatures, National Taiwan University, 1, sec 4, Roosevelt Road, Taipei, Taiwan, ROC 106. Email: westbroo@ntu.edu.tw
} 
This paper explores the extent to which online courses can replace more traditional approaches to teaching and learning in the twenty-first century by drawing on the experience of educational facilitators worldwide and my own experience of teaching online in Taiwan.

\section{The need for definition}

The first problem that emerges when we try to talk about e-learning in a global context is one of definition. Online learning, Internet-based learning, web-based learning and e-learning are used interchangeably by practitioners in the field (Capper, 2001). This lack of a simple definition betrays a much larger problem of definition that 'online learning' is currently experiencing. As practitioners struggle with already tight university budgets for computer technology that may be obsolete in less than two years' time, what is their rationale for going online? What kind of training will be available to faculty and students and what technical support will be available at every stage of the design, implementation and follow-up process? Who will the courses reach? Can online courses be offered off-campus? What systems will be implemented to ensure that quality courses are being offered? How can online courses meet the demands of the multiplicity of learning styles and take account of learners with special needs? How can courses be assessed online? How will they keep students interested, given that the drop-out rates for online courses are higher than for any other kind of course? (Beatty-Guenter, 2001). How will they differ from conventional courses in terms of design, timetabling, interaction with teachers and peers, content and assignments? Will the courses be synchronous or asynchronous, have chat rooms, discussion boards and email discussion forums? How will the achievements of virtual graduates be judged against conventional university graduates in the job market? What are the repercussions for a society of virtual communicators? In this paper it will only be possible to address a few of these questions, but we might begin with a discussion of general contexts for online learning.

\section{Ethical implications of online learning}

As an online learner with the IOE at the University of London, the convenience of online learning was immediately apparent to me. During the first two weeks of the course I was working in France, England and Taiwan. It would have been impossible for me to have taken this course had it not been online. I was also made aware of how fortunate I was that in each of these countries I was able to access computers and upload the necessary software quickly and easily. However, online learning is not the global solution that it pretends to be in terms of bridging geographical, and cultural, distances. One of the most serious hindrances to global online learning, as Lawrence E. Gladeieux argues, is that 'for much of the world, the promise of modern distance learning can only be realized with massive up-front investments in communications 
infrastructure' (Gladeieux, 2000, p. 351). Not all Governments are in a position to make the initial necessary investment to render online learning accessible to those in remote areas. The latter cannot, therefore, take advantage of these kinds of learning opportunities. More recent studies of the gap between the 'information rich' and the 'information poor' have demonstrated that this problem is not confined to third world countries (Angus et al., 2004). This failure of online learning to reach precisely those who need it most has raised a new ethical problem of twenty-first century technology generating even bigger cultural and class divisions than it pretends to bridge. In generating online courses, institutions should also be aware that they are generating international communities composed of people with different cultural backgrounds and expectations. Olliges and Mahfood suggest that new questions and problems will emerge as cyber communities become an increasingly prominent element in twenty-first century global society, 'ethics as a field of study will have a reawakening through the lens of virtual reality' (Olliges \& Mahfood, 2003, p. 15).

\section{Resources}

It has been argued that the world academy has been too slow to appropriate the technology that has already become incorporated into society in multifarious ways, and that this failure will be increasingly visible as the academy ignores the demands of the twenty-first century global market. Kay MacKeogh has noted that:

... while society in general may be changing rapidly, the conventional education system is still some way from adopting structures and processes appropriate for meeting the lifelong learning needs of a diverse population of disparate age groups, with varying domestic and work responsibilities, living often long distances from educational institutions. (MacKeogh, 2001, p. 223)

Joanne Capper has also argued that if the traditional universities are to have a future in online education, and remain competitive in a market in which virtual universities, such as Jones International University, are already succeeding, they will have to engage in some fast strategic planning. Capper argues:

The burgeoning need for just-in-time education and training has resulted in the creation of a vast and diverse marketplace of learners. Universities possess tremendous resources and a high level of credibility. If they can adopt a strong strategic vision of how and where online learning can reach the greatest number of potential students within their perceived mission, their future in the world of online education is very bright indeed. (Capper, 2001, p. 245)

Online courses have the potential to significantly increase the possibilities for cheap and fast research through access to ever expanding databases of e-texts, bibliographies and links to major holdings in university libraries around the world. In fact, this has been one of the most persuasive arguments for going online. However, Edward D. Garten has argued that in spite of the undeniably significant contribution that the Internet can make to learning, online resources will never replace traditional libraries because the Web lacks validation, information, appropriate organization, 
and effective retrieval systems (Garten, 2000). The weaknesses of Internet libraries that Garten notes are real enough. However, the rising costs of library storage space and the cutbacks in specialist retrieval staff that many academic libraries have experienced in the last decade mean that the paper library is becoming less and less efficient as a site of exploratory research. Many libraries are already engaged in transferring materials to electronic media, for both preservation and access purposes.

\section{Online vs. Traditional teaching}

In spite of the universal trend toward implementing some form of online learning, there remains an element of steady resistance to wholesale electronic teaching from students as well as teachers. Even those who have willingly endorsed online learning have found that it has not been the dream solution to the eternal problems of how best to teach. Garten has noted that:

Most educational technology introduced over the last fifty years has only supplemented and not supplanted traditional classroom instruction. Indeed, these technologies have without exception added to the cost of instruction, not reduced it. (Garten, 2000, p. 369)

Aside from the financial costs, teacher time and energy are important expenses that should be considered in any plan to introduce online learning. It is important that in generating new courses, time is allocated to reflection and development of the course; that any interactive work required as part of the course can be managed by the teacher; and that the course can be monitored for quality assessment. In response to the criticisms that many online courses lack appropriate quality controls, Paul Kelly and Lyn Roberts have argued persuasively that online courses can offer more structural and procedural transparency than traditional courses. The fact that a course is online means that assessment and development of the course itself is facilitated, as well as offering greater opportunities for feedback and staff development.

When a lecturer develops lessons for online delivery and/or coordination, the material is also available for judgment by and provision of constructive criticism from their peers and supervisors. Managers have more opportunity to view the progressive development of course materials. (Kelly \& Roberts, 2000, p. 96)

Where teachers are uncomfortable about being exposed in this way, passwords can easily be issued that allow only directors, teachers and students to access the course.

The possibilities and limitations of interaction at every level of the teaching and learning experience continues to be a major concern in the online debate. Those who promote online learning are willing to concede that there can be an overload of information with which to interact, as well as student questions and problems that must be dealt with. Most teachers, whose only electronic tool for interacting with students is email, already know the strain that responding to email questions and problems places on their research time. But if, as Beatty-Guenter maintains, 'the higher the levels of interactivity, the higher the course completion rates' (Beatty- 
Guenter, 2001), solutions will have to be found that enable teachers to satisfy their students' needs for interaction without draining vital research time. In recognition of the importance that teachers and students attribute to interaction in the learning environment, Anita Pincas reassures us that collaboration online has the potential to work even better than in traditional classrooms (Pincas, 1998). Greg Kearsley explains that online learning is, in fact, highly interactive - it is just a different kind of interaction:

Social skills are an important aspect of interacting via computer networks, especially when collaboration is involved. Alas, most people have little formal training in how to successfully interact or work with others; these are skills that are picked up incidentally through family or school life. To make things even more complicated, the social milieu of online activities is quite different from in-person interactions and requires new skills and behaviors. (Kearsley, 2000)

Kearsley and Schneider have developed their understanding of online interactivity to formulate what they call 'engagement theory'. They explain:

The difference between engagement and interactivity reflects the shift in thinking about computers in education as communication tools rather than some form of media delivery devices. Furthermore, engagement theory places a great deal of emphasis on providing an authentic (i.e., meaningful) setting for learning, something not present in previous models. (Kearsley \& Schneider, 1999)

Kearsley and Schneider argue persuasively that there are plenty of opportunities for meaningful interaction and collaborative learning that encourages collective cognitive responsibility. However, in the process of asserting the wonderful interactive possibilities of online learning we should take into account the negative aspects of online interaction that some teachers have observed. Robin Mason reports that in her Open University online course H802:

The students, many of whom became total converts to the value of collaborative learning in the early stages of the course, were definitely flagging by about four months into the course. The term 'collaboration fatigue' was coined to express their combination of appreciation but overload with the demands of collaborating online. (Mason, 1999, p. 7)

The students on this course were clearly pleased to have been relieved of their online collective cognitive responsibility. Collaboration, whether in class or online is a complex psycho-social phenomenon with its own inherent problems and possibilities that are difficult even for trained professionals to manage on-site in a classroom with the advantages of verbal, body and spoken language. In the process of trying to accommodate as many learning styles as possible in the design of online teaching models, it should emphasized that not everyone works best in a collaborative context (Hancock, 2004). In an online situation many more problems can arise, as most email users already know, and misunderstandings can result in collaborative crashes, creating damage that can not easily be repaired by an absent third party.

Another problem arises when we assume that university students are inherently self-regulating, responsible and organized learners. In their experience of online 
teaching, Yin et al. noted that about a third of their online students failed to submit their required weekly assignments, an unfortunate fact that they attributed to the absence of the physical structure that traditional classroom teaching and teacher presence lend to the learning experience: 'When students do not have the daily routine of physically coming to class, some fall into the trap of failing to schedule their own routine to complete their assignments' (Yin et al., 2002, p. 5). They suggest that appropriate motivational devices be used to encourage students to complete their coursework. Of course, this merely raises another problem-basedquestion of what exactly constitutes an appropriate motivational device? Clearly such students need to be taught not only new skills of how to manage online coursework but how to manage online learning per se as a preliminary to any online course that they may take.

What emerges from such studies is that online teaching requires substantial investment in manpower, resources and time. Olliges and Mahfood have conveniently paraphrased what they perceive to be critical elements that must be in place for successful online teaching and learning: 'commitment from the top, an environment that encourages experimentation and accepts failure, a collaboration/resource sharing attitude, an availability of resources for those instructors wanting to 'play' with technology and learning, a change in management strategy to ensure e-learning is adopted with 'minimal discomfort,' development support for instructors, and student support' (Olliges \& Mahfood, 2003, p. 7). Careful strategic planning of online learning is clearly needed, and the failure to lend it the time and energy required can have disastrous consequences all-round.

Julie Macdonald has argued that in the absence of appropriate training for online teaching there is a tendency to try to replicate traditional models of teaching and learning for web-based instruction, but that fundamental to the success of an online course is an acknowledgement that new media require new models (MacDonald, 2001). Kelly and Roberts make the important point: 'Not only do we need to learn how to teach differently, but we need to help our students to learn differently' (Kelly \& Roberts, 2000, p. 98). In spite of his enthusiastic belief in online courses as the dominant educational platforms for the twenty-first century, Kearsley cautions:

Because online teaching is so different, even experienced teachers will require considerable practice before being good online instructors. So it is going to be a while before most teachers are good at this. Organizations and institutions offering online courses should be mindful of the time period required to properly prepare their teachers to teach in cyberspace. (Kearsley, 2000)

\section{Online courses in Taiwan}

In the fall semester of 2003 I ran a course in English composition for third-year English literature students at NTU. My intention for this course was that it should contain an element of online learning that would enable access to the course outside of the weekly three-hour seminar session. I did not merely want to replicate what was happening in class, rather, provide something that would complement it. The 
students were already learning the core elements of English composition in the weekly seminars and were engaged in a project about twentieth-century adaptations of Shakespeare's plays, to which we allocated some class time each week. The best idea seemed to be to hand the online element over to the students themselves as a forum that they would not only use to share resources for their projects and other aspects of the course, but through which they could also interact with each other about more general problems, and possible solutions, concerning their English compositions. The online element was conceived as asynchronous in order to make it as flexible and easy to manage as possible and to avoid the pitfalls of some students wanting to dominate the debate and others trying to use the forum for their own, tangential, issues. However, by adopting an asynchronous approach I was aware of the fact that I was depriving the students of an extra opportunity to discover 'best practice' in online collaboration.

The students were given formal instruction about how to use the course site by the computer centre staff. They worked in small groups to upload relevant information each week, and their colleagues were invited to read the information and discuss its usefulness, or not, both online and in subsequent seminars.

There were some initial technological problems due to the incompatibility of my own software with that used by the computer centre, and the fact that only a classical Mandarin Chinese version of the software was available to me. Initially, I uploaded some useful web sites and gave the students cues about how to make the best use of them, but I then handed it over to the students. Instead of preaching the rules, I wanted them to discover the reasons for the rules through the process of working online. In subsequent seminars some students said that they had not had sufficient time to fully engage with the sites that their colleagues had uploaded. When confronted, students confessed that the problem was that their classmates were not filtering the information and explaining exactly which links were important and why, and that they were failing to suggest how they might use them. From this experience the students learned that it was important to have a directed approach not just to finding relevant material, but in presenting it to other learners. Subsequently, all of the students uploaded introductions to their sites without having to be asked to do so. This small change in their online behaviour resulted in much more lively class discussion and feedback about the sites that were being presented each week. There was a discernible collective responsibility about uploading only sites that pertained to their project work. I didn't have to caution any student about uploading irrelevant and distracting material. Since this was my first engagement with online learning, I decided to enlist the help of one of my more experienced colleagues by discussing approaches with her.

At National Taiwan University the Ceiba online platform for learning has been up and running since 1990. Although there was no teacher input in the initial design stages of the software, teachers were subsequently invited to test it and, as the strengths and weaknesses of Ceiba emerged, the software was developed accordingly. In 2003 Ceiba version 4 was launched. My colleague, Dr Susan Chou, who has been working at NTU for 32 years, was one of those teachers who participated in the 
testing of Ceiba. She currently uses Ceiba as a supplement to her in-class teaching of English language and culture to second-language learners. She explained:

I use online as computer assisted language learning. ... I do my in class teaching and then I put homework materials on my web site. For my listening comprehension web site, every week I put a five minute audio file, sound file, for transcription, and then about another 15 minutes of fairy tales ... and ask the student to write about 300 words, and then I choose the web site and ask the students to read that particular web site that I chose and write a comment. In other words I get three kinds of exercise every week and I have to correct them.

I pointed out that her online courses clearly required a lot of correcting each week, but she argued that online correcting necessitated a different approach. Because of the volume she marked more strategically, noting only major problems and focusing on giving encouragement to students. She found that this online correction strategy did not affect the students adversely. By not overloading them with critical comments, the students showed more signs of progress. She also pointed out that in giving the students responsibility for their own online learning, more of the students did all of the homework required. She felt that it was important in the initial stages of online teaching not to make too many demands on the students in terms of quality and length of their contributions, but to respond with positive criticism to every contribution. When introducing students to online learning, the important point was to get them hooked and to open them up to the wonderful resources for learning English that were available on the web. When I asked her if she would ever consider running a course wholly online she was adamant that such a course could not work because of the cultural context for learning in Taiwan:

... in our culture students were pushed, only work under the teachers, so if it's a purely online course there's no control, they get no help, I don't know what would happen. It would be disastrous.

In their study of autonomous language learning at Hong Kong Polytechnic University Chan, Spratt and Humphreys arrived at a similar conclusion. They found that students had a 'well-defined view of the teacher's role and responsibilities ... a strong preference for a dominant teacher role and thus a relatively less autonomous student role' (Chan et al., 2002, p. 12).

I decided to ask my own students how they felt about online learning, and I did this through a short questionnaire. Of the small sample of eight students, five said that they had taken five-six courses with an online element. They enjoyed the convenience of having teacher materials and schedules on the web that they could return to easily without having to take notes in class. They enjoyed exchanging ideas, getting information without leaving their desks and being able to upload information for each other. One student suggested that he liked using the web for making contributions because he was too shy to contribute in class. This response accords with the conclusions of a study of online learning conducted at the City University of Hong Kong during 2003. Downing and Chim discovered that online learning was especially suited to reflectors, often perceived to be introverts in the traditional 
classroom learning context, and that the use of 'online (blended) learning significantly improves student satisfaction levels for reflectors' (Downing \& Chim, 2004, p. 273).

When I asked my students what they did not like about online learning their responses were mostly related to either technological conventions or failures. Common problems were having to key-in multiple password entries, link failures, computer breakdown and the low grades that followed from not being able to upload their reports successfully. Ali's study of practices and perceptions of online learning has recently highlighted the learning problems that ensue when difficulties encountered with the technology used competes for attention with the content of any course. He observes that 'In online forums, it is not uncommon to see at least half of discussions are about the technology issues, instead of content' (Ali, 2003, p. 44). Along with the articulated frustrations with using technology, students complained about associated time-factors. Some students felt that it took too long to find valuable web sites, and frustration was also incurred from missing late contributions from other students. Not being able to meet colleagues or teachers was also perceived as a deficiency in online learning, for which no amount of sophisticated technology could compensate.

When asked if they would consider taking a degree course that was entirely online five of the students said that they did not wish to take an online degree. The most common reason given for this response was that they enjoyed face to face interaction with their teachers and colleagues. One student commented that although it was possible to interact on the net, he really preferred to meet people in person. Another student commented that he would prefer to work alone rather than take an online degree, if that was all that was available. Another student commented that she already knew how to search the Internet for knowledge so probably wouldn't take an online course, betraying a rather narrow understanding of the potential of online courses. Clearly for these students real social interaction was an important factor in their enjoyment of the courses they took.

When asked what problems, if any, they had encountered in online learning, one student responded that knowing that materials were online meant that he was not as responsive in class. Some students suffered from information overload, whilst others registered concern about the strain that online learning was placing on their eyes. One of the students preferred class teaching because answers were provided immediately, thereby erasing the frustration of having to wait for email responses. The questionnaire invited the students to make any further comments about any aspect of their experience of online learning. One student felt that the attitude of the participants in online courses was vital, and that if everyone in the class is working toward the same goal then it can be very exciting. Introductions to recommended web sites were felt to be useful as a means of focusing the reader, and the filtering of available web sites for each other was a helpful way of reducing information overload. One student said that having filtered information made online learning particularly 'attractive'. Accepting the importance of technology in the twenty-first century, and the probability of ever-increasing online courses, one student said that she still 
believed in the importance of classroom teaching and learning, adding that 'going to classes is a chance to get out of my dorm, smell the flowers, and finally not to have to face my computer'. Another student pointed out that some courses were simply not suited to online learning, giving the example of Public Speaking, whilst other courses that involved reading and writing could more easily be adapted for learning online, but he added 'I believe real personal interaction is necessary'.

\section{Conclusion}

Whilst universities may be anxious to catch up with the global trends in online education, the complex issues that attend online teaching and learning must first be addressed. As the studies in this paper have shown, for online courses to be effective there needs to be appropriate training and support both for teachers and learners as they develop new strategies in response to new technologies for learning. It is also apparent that support structures need to be implemented at every level of the online process, and that these may vary according to the cultural context in which online opportunities are being provided. Although a number of recent studies have endorsed the commonly held perception that eastern students are less autonomous than western students, what my own study revealed was that the students merely preferred more direct personal interaction in their learning process that traditional classroom contexts readily provided. It may simply be a case of students wanting what they are used to, but it is also the case that they are very alert to the advantages of personal interaction that online learning is simply failing to provide. With appropriate support from the teacher the majority of the students enjoyed the extra flexibility and opportunities that online learning presented, technological frustrations aside, and responded well to integrated tasks that extended from online contexts, to more social, traditional teaching, contexts.

In the meantime, the Open University is already conducting virtual graduations in line with the ethos of its online courses. In the virtual graduation ceremony students participate in a synchronous online event, as Mary Thorpe reports, 'receiving their masters award at a distance, via a virtual VC handshake, rather than a real one' (Thorpe, 2000, p. 11). The problem with this idea is that the experience of graduation is not just about shaking the VC's hand, it is about sharing an experience with friends and relatives. It is the culmination of the process of organizing the tickets, hiring the gowns, seeing the proud faces of relatives, enjoying that free meal at the end of a day in celebration of a hard-earned academic accolade. Since an entirely different approach to teaching and learning is required in every other aspect of online courses, perhaps a wholly new way of celebrating the achievement of the learning goal is in order. It seems that the virtual graduation is doing two things entirely against the ethos of online teaching and learning: by replicating traditional models and including elements that are redundant even in traditional contexts.

Online learning is not the first choice for most of my students now, but they will soon have to manage their families and careers. In order to maintain their 
professional development they may well find that the convenience of online learning will make it a more attractive choice.

\section{Acknowledgements}

Thanks are due to Dr Susan Chou, the students in my third-year English composition class (2003) and to the Institute of Education, the University of London, for giving me the opportunity to participate in their online teaching and learning course.

\section{References}

Ali, A. (2003) Instructional design online instruction: practices and perception, Tech Trends, 47(5), $42-45$.

Angus, L., Snyder, I. \& Sutherland-Smith, W. (2004) ICT and educational (dis)advantage: families, computers and contemporary social and educational inequalities, British fournal of Sociology of Education, 25(1), 3-18.

Beatty-Guenter, P. (2001) Distance education: does access overrride success? Available online at: www.cirpa-acpri.ca/prevConferences/victoria2001/papers/bg_paper.htm (accessed $21 \mathrm{March}$ 2004).

Capper, J. (2001) The emerging market for online learning: insights from the corporate sector, European Fournal of Education, 36(2), 237-245.

Chan, V., Spratt, M. \& Humphreys, G. (2002) Autonomous language learning: Hong Kong tertiary students' attitudes and behaviours, Evaluation and Research in Education, 16(1), $1-18$.

Chen, T. (2003) Recommendations for creating and maintaining effective networked learning communities: a review of the literature, International fournal of Instructional Media, 30(1), $35-44$.

DfES/0455/2003 (July, 2003) Towards a unified e-learning strategy: consultation document executive summary. Available online at: http://www.dfes.gov.uk/CONSULTATIONS/ConResults.cfm? consultationId $=774$ (accessed 29 March 2004).

Downing, K. \& Chim, T. M. (2004) Reflectors as online extraverts?, Educational Studies, 30(3), 265-276.

Garten, E. D. (2000) Providing intellectual resources through technology to transnational virtual universities: good practice and lessons learned from world-class examples, Higher Education in Europe, $\mathrm{XXV}(3), 361-371$.

Gladeieux, L. E. (2000) Global online learning: hope or hype?, Higher Education in Europe, $\mathrm{XXV}(3), 351-353$.

Hancock, D. (2004) Cooperative learning and peer orientation effects on motivation and achievement, fournal of Educational Research, 97(3), 159-166.

Hicks, M., Reid, I. \& Rogmor, G. (2001) Enhancing online teaching: designing responsive learning environments, The International fournal for Academic Development, 6(2), 143-151.

Hopkinson, B. (2002) Interaction in online learning. Available online at: www.ioe.ac.uk/schools/ leid/oet/OET\%20html\%202001\%20essay\%20docs/Hopkinson_B.htm (accessed 21 March 2004).

Jones International University (JIU) (web site) www.jonesinternational.edu. (accessed 21 March 2004). 
Kearsley, G. \& Schneiderman, B. (1999) Engagement theory: a framework for technology-based teaching and learning. Available online at: http://home.sprynet.com/ gkearsley/engage.htm (accessed 28 March 2004).

Kearsley, G. (2000) Learning and teaching in cyberspace. Available online at: http://home.sprynet.com/ gkearsley/chapts.htm\#chap6 (accessed 28 March 2004).

Kelly, P. \& Roberts, L. (2000) Challenges for university administrators in the online world, Perspectives, 4(4), 95-99.

MacDonald, J. (2001) Online learning: a radical pedagogy?, Adults Learning, 12(5), 20-23.

MacKeogh, K. (2001) National strategies for the promotion of online learning in higher education, European fournal of Education, 36(2), 223-236.

Mason, R. (1999) IET's masters in open and distance education: what have we learned? Available online at: http://iet.open.ac.uk/pp/r.d.mason/downloads/MAEval.PDF (accessed $28 \mathrm{March}$ 2004).

Nicolay, J. A. (2002) Group assessment in the online learning environment, New Directions for Teaching and Learning, 91(Fall), 43-52.

Olliges, R. \& Mahfood, S. (2003) Teaching and learning in the new millenium: transformative technologies in a transformable world, Communication Research Trends, 22(2), 3-28.

Pincas, A. (1998) Successful online course design: virtual frameworks for discourse construction, Educational Technology \& Society, 1(1) 14-25. Available online at: http://ifets.fit.fraunhofer.de/periodical/vol_1_98/ets_1_1_eng.pdf (accessed 21 March 2004).

Pincas, A. (2000) Features of online discourse for education, Learning Technology, 2(1). Available online at: http://lttf.ieee.org/learn_tech/issues/january2000/index.html (accessed $21 \mathrm{March}$ 2004).

Thorpe, M. (2000) Online learning not just an e-university idea, Adults Learning, 11(8), 11-12.

Yin, R. L., Urven, L. E., Schramm, R. M. \& Friedman, S. J. (2002) Assessing the consequences of online learning: issues, problems, and opportunities at the University of Wisconsin-WhiteWhitewater, Assessment Update, 14(2), 4-13. 
Copyright of Teaching in Higher Education is the property of Routledge and its content may not be copied or emailed to multiple sites or posted to a listserv without the copyright holder's express written permission. However, users may print, download, or email articles for individual use. 